\title{
Coherent promotion of renewables under a carbon emissions cap
}

\author{
Philippe Thalmann, EPFL, 28.03.2015
}

The German energy transition, with its massive subsidization of variable renewable electricity generation (wind, solar, etc.) leading to its dramatic expansion, has spurred controversy proportional to its ambitions. This chapter focuses on just one critique addressed against it: that it is actually bad for the climate. This critique was levelled prominently by Professor Joachim Weimann of the Otto-von-Guericke University in Magdeburg and Professor Robert Stavins of Harvard University's Kennedy School. ${ }^{1}$ They argue that promoting solar and wind electricity does not reduce any $\mathrm{CO}_{2}$ emissions because coal-fired plants forced to reduce their production would merely sell unused emissions allowances to some other emitter. The total level of emissions is always equal to the cap, whatever measure is taken to reduce abatement costs. Moreover, by depressing the price of emissions allowances, subsidizing renewables actually forces other, cheaper, mitigation technologies out of the market, which reduces important future mitigation options. It even helps the dirtiest generation technology, old lignite power plants. In the end, Weimann blames the German promotion of renewables for being the main if not only cause for the difficulties of the European Union Emission Trading Scheme (EU ETS).

A part of the argument may seem paradoxical: if promoting renewables frees emissions allowances by taking electricity demand away from coal-fired plants, how could that lead coalfired plants to produce more electricity? That is not possible as such, of course, but promoting renewable could still help coal-fired plants. Imagine a merit order curve that starts with coalfired plants with gradually rising marginal generation costs, including the carbon price, until it reaches the level where gas-fired plants become the cheaper option. Promoting renewables with guaranteed market uptake leads to a leftward shift of the electricity demand for coal- and gas-fired plants. Gas-fired plants are forced first to reduce their production, which frees emissions allowances (and is bad for system stability as gas-fired power plants can ramp up production the fastest). Their price goes down, which helps coal-fired plants take away some production from the remaining gas-fired plants. In fact, the share of natural gas in the German electricity mix was about the same in 2014 as in the early 2000 , while the share of renewables grew from $6.6 \%$ to $25.8 \%{ }^{2}$ The increase in renewable energy production $(+120 \mathrm{TWh})$ really accounted for the increased total generation (+34 TWh) and it replaced nuclear generation ($73 \mathrm{TWh}$ ). Total coal-based generation actually declined by $26 \mathrm{TWh}$. When renewables replace nuclear power, which is of course one of the purposes of their promotion in the context of a phasing out of nuclear power, they have no impact whatsoever on the carbon price.

\footnotetext{
1 Joachim Weimann, 'Der $\mathrm{CO}_{2}$-Emissionshandel im Zeitalter der Energiewende (2013) 138 Orientierung zur Wirtschafts- und Gesellschaftspolitik 39-45; Robert N. Stavins, 'The problem with EU renewables (2014) 31 The Environmental Forum 14.

$2<$ http://www.ag-energiebilanzen.de> accessed 27 March 2015.
} 
Weimann and Stavins' argument that promoting a particular abatement technology under an emissions cap is both inefficient and ineffective is quite convincing in a perfect world, a world where the central planner efficiently sets an overall cap for $\mathrm{CO}_{2}$ emissions and gradually lowers it as mitigation options are improved. A world where market actors anticipate smoothly rising carbon prices and invest in abatement technologies accordingly. A world where mitigation options compete on a level playing field. In such a world, one instrument - the EU ETS - is all that is needed for one goal - a smooth reduction path for $\mathrm{CO}_{2}$ emissions. In the real world, all these assumptions are invalidated. First, there is no central planner setting emission caps efficiently but instead there is a political system where short-term industrial and employment interests weigh more heavily than the interests of future generations. As a result, the cap is set much higher than it would be by a forward-looking altruistic planner. ${ }^{3}$ The consequence is a low carbon price. A business cycle downturn, which reduces the demand for carbon intensive goods, further depresses the carbon price when the cap is not adjusted, and of course it cannot be tightened when the economy is already struggling. All this leads to low and volatile carbon prices, which discourage emitters from investing in the research, development and deployment of long-lived abatement options. There is too little investment in these options compared to the perfect world, which justifies compensatory support by the public sector.

The support for renewables is even more warranted when carbon intensive alternatives benefit from subsidies for other reasons (regional support for coal extraction and transportation for instance). And it is more warranted when the technologies face a steep learning curve with spill over effects. The German promotion of variable renewables lowered the cost of these technologies and led to the spread of their diffusion also outside of the area under the European emissions cap. This is possibly the most significant contribution of Germany to slowing down climate change. Finally, the political system that will set the next caps is likely to follow a more ambitious emissions reduction path now that more abatement options are available at lower costs.

In short, promoting renewables was not necessarily inefficient in the real world and it was certainly not ineffective at a global level. There remains Weimann and Stavins' argument that it was ineffective at the level of the area under the European emissions cap, at least as long as it does not lead to a change in the cap. In a perfect world, emissions will always reach the cap. In the real world of the EU ETS, the over-allocation of emissions allowances was so massive in the first two phases that the cap could not be reached. When the cap is not reached, any instrument that encourages abatement leads actually to a reduction in emissions. Now one could argue that the promotion of renewables in Germany led to such a decrease in the demand for certificates that it is really responsible for the over-allocation. At least it would have had an effect on $\mathrm{CO}_{2}$ emissions. Anyway, that would be giving too much credit to the expansion of renewables in Germany and Weimann does not make that argument. Still, it is true that promoting renewables contributes to the glut of emissions allowances.

\footnotetext{
3 See also R. Pearse and S. Böhm, 'Ten reasons why carbon markets will not bring about radical emissions reduction' (2015) Carbon Management 1-13.
} 
This shows that the promotion of renewable power is most effective when it is accompanied by the withdrawal of allowances. Of course, it is difficult to determine how many. To the extent that renewables replace nuclear power, no allowances are freed. When they replace thermal power plants, the quantity of $\mathrm{CO}_{2}$ emissions economized depends on the technology replaced. It need not be the most carbon-intensive technology, as shown earlier. Funding the withdrawal of allowances is a lesser issue when they are so abundant that they trade almost for free.

In conclusion, the promotion of electricity generation from renewables cannot be thrown off simply because it would be inefficient and ineffective in an ideal world with simple goals and perfect markets. There are many goods arguments in favour of such a policy in the real world. Nevertheless, it should be designed carefully and it can be made more effective if the emissions allowances it liberates are taken out of the market.

Published as:

Thalmann, Philippe, "Coherent promotion of renewables under a carbon emissions cap", in: Raphael J. Heffron and Gavin F.M. Little (eds), Delivering Energy Policy in the EU and US: A Multi-Disciplinary Reader, Edinburgh University Press, Edinburgh, 2016, chap. 49 (ISBN: 9780748696789 / 9780748696796 )

https://edinburghuniversitypress.com/book-delivering-energy-law-and-policy-in-the-eu-andthe-us.html 